\title{
Avaliação do hábito alimentar de PRATICANTES DE ATIVIDADE FÍSICA MATINAL
}

\author{
Tcherena Amorim Brasil1,2 tabnut2001@yahoo.com.br \\ José Alberto Pinto',2 japinto@ufv.br \\ Paula Guedes Cocate ${ }^{1,2}$ guedescocate@yahoo.com.br \\ Renata Pires Chácara',2 renatachp@yahoo.com.br \\ João Carlos Bouzas Marins',2 jcbouzas@ufv.br
}

doi:10.3900/fpi.8.3.153.p

Brasil TA, Pinto JA, Cocate PG, Chácara RP, MarinsJCB. Avaliação do hábito alimentar de praticantes de atividade física matinal. Fit Perf J. 2009 mai-jun;8(3):153-63.

\section{RESUMO}

Introdução: Determinar e avaliar a prática habitual do desjejum como hábito e refeição pré-exercício de praticantes de atividade física matinal. Materiais e Métodos: Foram avaliados 500 praticantes de atividade física, com idades variando de 15 a 77 anos. $O$ procedimento experimental empregado correspondeu ao da técnica observacional por questionário simples. Resultados: Um total de $82,2 \%$ dos sujeitos realiza algum tipo de desjejum pré-exercício. Entre os alimentos mais consumidos, estão frutas (55,2\%), pão (72,4\%), café (51,5\%), leite com achocolatado $(38,68 \%)$ e frios (36\%). A maior parte dos entrevistados $(66,6 \%)$ acredita fazer uma escolha correta dos alimentos; contudo foi registrado o consumo de alimentos não recomendados. O tempo de ingestão mais predominante (34\%) foi entre $30 \mathrm{~min}$ e $45 \mathrm{~min}$, previamente ao exercício. As manifestações fisiológicas mais observadas durante a prática de exercícios foram: tonteira $(42,2 \%)$, sonolência $(37,2 \%)$, sede intensa $(31,4 \%)$ e nenhuma $(40,6 \%)$. $\bigcirc$ consumo de suplementos foi indicado por 28,2\% da amostra. Discussão: Os praticantes de atividade física matinal, habitualmente consomem algum alimento antes da prática de exercícios. É necessária uma orientação nutricional para maior esclarecimento em relação à escolha dos alimentos corretos para comporem uma refeição pré-exercício.

\section{PALAVRAS-CHAVE}

Nutrição, Recomendações Nutricionais, Glicemia.

\footnotetext{
1 Universidade Federal de Viçosa - UFV - Departamento de Educação Física - LAPEH - Viçosa - Brasil

${ }^{2} \mathrm{CNPq}$ - Bolsa de Iniciação Científica - Brasil
}

\author{
Copyright(C 2009 por Colégio Brasileiro de Atividade Física, Saúde e Esporte
}

Fit Perf J | Rio de Janeiro | 8 | 3 | 153-163 | mai/jun 2009 


\section{EATING hABIT EVALUATION OF APPRENTICES TO MORNING PHYSICAL ACTIVITY}

\section{ABSTRACT}

Introduction: Determinate and evaluate the habitual practice of breakfast and meal pre-exercise of apprentices to morning physical activity. Materials and Methods: It was appraised 500 apprentices of physical activity, with ages among 15 to 77 years. The employed experimental procedure corresponded of the observational technique for simple questionnaire. Results: In a total, $82.2 \%$ of people accomplishes some type of breakfast pre-exercise. The foods more consumed are fruits (55.2\%), bread (72.4\%), coffee (51.5\%), milk with chocolate (38.68\%) and dairy products (36\%). Most of interviewees (66.6\%) believes that make a correct choice of the foods. However, it was registered the consumption of no recommended foods. The predominant time of ingestion (34\%) it was between 30 and 45 minutes, previous the exercise. The physiologic manifestations occurred more during the practice of exercises were: dizziness (42.2\%), somnolence (37.2\%), intense thirst (31.4\%) and none (40.6\%). The supplements consumption was indicated for $28.2 \%$ of the sample. Discussion: The apprentices of morning physical activity habitually consume some food before practice exercises. But, It's necessary a nutritional orientation for better explanation in relation the correct choice of foods to compose a pre-exercise meal.

\section{KEYWORDS}

Nutrition, Nutrition Policy, Blood Glucose.

\section{Evaluación del costumbre alimentar antes de LA ACtividad física matinal \\ RESUMEN}

Introducción: Determinar y evaluar la conducta habitual de alimentación antes de un ejercicio matinal. Materiales y Métodos: Fueron evalvados 500 practicantes de actividad física, con edades entre 15 y 77 años. El procedimiento experimental adoptado fue de técnica observación por cuestionario simple. Resultados: Un total de $82,2 \%$ de los sujetos realizaron algún tipo de comida antes del ejercicio. Los alimentos más consumidos fueron frutas $(55,2 \%)$, pan $(72,4 \%)$, café $(51,5 \%)$, leche con chocolate $(38,68 \%)$ y embutidos $(36 \%)$. La mayor parte de los sujetos $(66,6 \%)$ acreditan hacer una elección correcta de los alimentos. Sin embargo, hay registros de consumo de alimentos que no están recomendados. El tiempo de consumo más frecuente (34\%) fue entre 30 y 45 minutos, antes del ejercicio. Los síntomas fisiológicos más frecuentes durante la práctica de ejercicios fueron: mareo $(42,2 \%)$, sueño $(37,2 \%)$, mucha sed $(31,4 \%)$ y ningún problema $(40,6 \%)$. El consumo de suplementos fue apuntado por $28,2 \%$ de la muestra. Discusión: Los practicantes de actividad física matinal habitualmente ingieren algún alimento antes de empezar la práctica de ejercicios. Es necesaria una orientación nutricional para un mayor aclaramiento en relación a la elección correcta de los alimentos que deben componer una comida antes de empezar un ejercicio.

\section{PALABRAS CLAVE}

Nutrición, Política Nutricional, Glucosa de la Sangre.

\section{INTRODUÇÃO}

Os hábitos alimentares estão entre os aspectos mais antigos e profundamente intrínsecos em várias culturas, exercendo forte influência no comportamento das pessoas. Esses hábitos baseiam-se na disponibilidade alimentar, na economia, nas crenças e nos significados que cada pessoa atribui aos alimentos e, em determinadas condições, podem produzir distúrbios alimentares que influenciam o rendimento ${ }^{\mathbf{1 , 2}}$.

Tradicionalmente, tem-se como recomendação nutricional básica a realização de seis refeições diárias, não sendo aconselhável concentrar a alimentação em poucas refeições. De todas as refeições em que o ser humano divide sua ingestão diária de alimentos, o desjejum ou café da manhã é considerado a mais importante, estando associado à função cognitiva ${ }^{3}$, porém é a mais inconstan$t^{4}$. Enquanto, em certos países, é um hábito, em outros é apenas uma opção saudável ${ }^{\mathbf{4}}$.

A realização da refeição pré-exercício é indicada, principalmente, pela manhã, a fim de evitar um quadro de hipoglicemia durante a atividade física, visto que os estoques de glicogênio hepático estão depletados 5 . Outros objetivos incluem restabelecer continuamente o glicogênio muscular durante o período de repouso que antecede o exercício, manter a homeostase hídrica e evitar a fome.

Considerando as condições habituais de calor no Brasil, as recomendações para a prática de exercício físico são referentes aos horários extremos do dia, ou seja, pela manhã, no final da tarde ou à noite. Pela manhã, em especial, o período mais comum varia de $6 \mathrm{~h}$ às $9 \mathrm{~h}$ 
e o praticante tem, como condição de normalidade, um período de repouso (sono) de cerca de $8 \mathrm{~h}$ a $10 \mathrm{~h}$, em estado de jejum nesse período.

Existe um consenso ${ }^{\mathbf{6 , 7}, \mathbf{8}, 9}$ de que deve haver um consumo de alimentos previamente ao exercício, porém as recomendações são de perfil geral, a qualquer hora do dia. Contudo, essas diretrizes nem sempre podem ser aplicadas quando da prática do exercício matinal, principalmente nas primeiras horas da manhã, entre $5 \mathrm{~h}$ e $8 \mathrm{~h}$ Brasil et al. ${ }^{10}$ afirmam que praticantes de atividade física, seja com objetivos estéticos, de saúde ou competitivo, optam por fazer o treinamento sem nenhum consumo prévio de alimentos.

O conhecimento dos hábitos alimentares de atletas e esportistas, em especial em sua primeira refeição, é fundamental para uma adequada intervenção nutricional na busca de melhorar o treinamento e a performance ${ }^{\mathbf{6}, 11,12,13}$. No entanto, existe um bom número de estudos de nutrição esportiva voltados para o comportamento dietético adotado ao longo de todo o dia, em várias modalidades, como, por exemplo, em corredores quenianos ${ }^{14}$, levantadores de peso brasileiros ${ }^{15}$ ou ciclistas, tanto em período de treinamento como em competição ${ }^{16}$. Por outro lado, estudos voltados para hábitos e padrões alimentares relacionados ao exercício matinal são pouco estudados.

O comportamento nutricional adotado por uma pessoa sofre influência de uma série de fatores, ente eles o grande número de informações sobre alimentação e nutrição que são divulgadas, muitas vezes, através de meios não-científicos ${ }^{2}$, ou mesmo por seus treinadores 17,18. Soma-se a isso a existência de maus hábitos alimentares, a falta de acesso a um nutricionista, assim como um conhecimento limitado por parte das pessoas em relação à sua alimentação, levando à escolha de alimentos inadequados na sua refeição prévia ao exercício. Cabe destacar que, em muitos casos, as condutas nutricionais em período de treinamento são semelhantes às adotadas em competição, como evidenciado com um grupo de ciclistas de elite ${ }^{16}$. Assim, as condutas equivocadas em treinamento serão repetidas na competição.

Conhecer as condutas nutricionais que os praticantes de atividade física estão adotando antes de iniciarem uma sessão de exercícios matinal, avaliando ainda a composição dessa refeição (se está adequada ou não), torna-se importante para estabelecer campanhas de orientação sobre a conduta nutricional correta. Isso pode influenciar diretamente a performance e o bem-estar, tendo em vista que condutas inadequadas podem desencadear manifestações fisiológicas associadas à hipoglicemia e desidratação. Desta forma, o objetivo deste estudo foi determinar e avaliar a prática do desjejum como hábito e refeição pré-exercício de praticantes de atividade física matinal.

\section{MATERIAIS E MÉTODOS}

$\bigcirc$ procedimento experimental empregado correspondeu ao da técnica observacional por questionário simples, através de um conjunto de perguntas objetivas e discursivas sobre a temática de práticas alimentares e de hidratação de forma prévia à realização de uma atividade física no período da manhã, visando detectar a realidade do comportamento nutricional adotado pela população praticante de atividade física. $\bigcirc$ procedimento adotado tomou por base outros trabalhos que visavam identificar os hábitos sobre hidratação em diferentes populações, como em lutadores de jiu-jítsu ${ }^{19}$, caratecas $^{20}$, judocas ${ }^{21}$ e atletas universitários ${ }^{\mathbf{2 2}}$, assim como o consumo de recursos ergogênicos e suplementos alimentares em praticantes de musculação ${ }^{23}$ e em atletas de alto rendimento ${ }^{11}$.

\section{Características da amostra}

Foram avaliados 500 praticantes de diferentes modalidades de atividade física, com idades variando de 15 a 77 anos. Desse número, cerca de 20\% estavam em competição quando foram abordados, e os demais se encontravam em treinamento. $\bigcirc$ processo de seleção dos sujeitos foi de caráter aleatório, não havendo restrição de modalidades esportivas. No quadro 1 é apresentada a distribuição dos entrevistados segundo a faixa etária.

Os avaliados eram provenientes de 16 cidades dos estados da Federação, como Minas Gerais $(49,6 \%)$ e Espírito Santo (34,8\%), que concentraram a maior parte dos dados, incluindo ainda representantes do Mato Grosso do Sul, Goiás, São Paulo, Rio de Janeiro e Distrito Federal, totalizando 15,6\%, durante o biênio 2004/2005.

\section{Modelo de questionário}

Este estudo analisou o comportamento alimentar na primeira refeição do dia, o café-da-manhã ou desjejum, como refeição pré-exercício, por meio de um questionário que foi validado por duas professoras do Departamento de Nutrição da UFV e um professor

\section{Quadro 1 - Distribuição da amostra segundo faixas} etárias

\begin{tabular}{lc}
\hline faixa etária & distribuição percentual (\%) \\
\hline 15 a 20 anos & 24,2 \\
21 a 25 anos & 21,0 \\
26 a 30 anos & 12,4 \\
31 a 35 anos & 6,6 \\
36 a 40 anos & 4,0 \\
41 a 45 anos & 6,8 \\
46 a 50 anos & 4,6 \\
51 a 55 anos & 8,2 \\
56 a 60 anos & 3,2 \\
61 a 65 anos & 4,2 \\
$>65$ anos & 4,6 \\
\hline
\end{tabular}


do Departamento de Educação Física da mesma universidade. $O$ questionário constava de 15 questões, abordando os seguintes aspectos: existência do hábito de realizar o desiejum antes da atividade física; opinião do avaliado sobre a composição dessa refeição; quanto tempo antes do exercício a refeição era realizada; tipo de modalidade, duração do exercício, e intensidade da atividade física; aparecimento de sintomas durante a prática do exercício físico; hábito de hidratação; momentos em que a hidratação era realizada e solução utilizada; e o consumo de suplementos nutricionais, citando-os em caso afirmativo.

O questionário deste estudo é do tipo História Alimentar, com o diferencial de que não avalia todas as refeições de um dia inteiro, mas apenas a primeira, considerada uma refeição pré-exercício, visto que sua composição é capaz de determinar o bem-estar e o desempenho dos praticantes de atividade física matinal. Este tipo de levantamento por História Alimentar busca conhecer o consumo habitual dos indivíduos ${ }^{24}$.

\section{Tratamento estatístico}

O tratamento estatístico para a análise dos dados ocorreu por meio de uma análise descritiva, além de uma abordagem por índice de resposta por meio do percentual ou frequência.

\section{RESULTADOS}

A primeira pergunta investigou a existência do hábito de consumir algum alimento antes da prática de exercícios. Os resultados apresentados indicaram que $82,2 \%$ dos entrevistados $(n=411)$ ingerem algum tipo de alimento antes do exercício, ou seja, 17,8\% realizam a atividade física em jejum.

A segunda pergunta visava conhecer os alimentos que faziam parte da refeição pré-exercício dos entrevistados. Os resultados para esta questão mostraram que, entre os alimentos sólidos, as frutas compõem o

Figura 1 - Tempo entre ingestão e início da atividade física

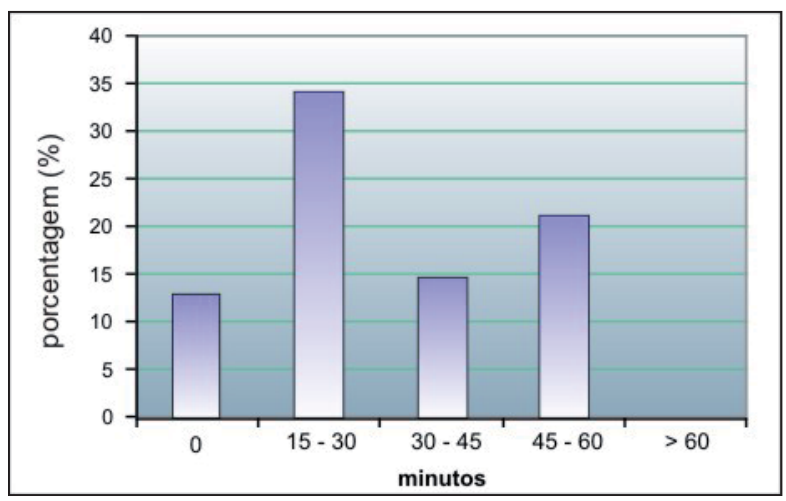

desjejum de $67,15 \%$ dos entrevistados que realizam essa refeição, em conjunto com o pão, este com mais de $88,07 \%$.

A terceira pergunta aborda o conhecimento dos entrevistados sobre a adequação ou não da sua refeição prévia ao exercício. Os resultados mostram que a grande maioria dos entrevistados ( $n=333$ ou $66,66 \%$ ) sustenta a ideia de que sua refeição pré-exercício contém os alimentos corretos.

A quarta pergunta questionava a opinião sobre o caféda-manhã ideal para ser ingerido antes da atividade física. A fruta e o pão foram os mais citados, respectivamente com $86,6 \%$ e $69,3 \%$ de prevalência de respostas. Já em relação aos alimentos líquidos, ainda prevalece o leite e suas preparações $(59,7 \%)$.

A quinta pergunta buscou identificar qual o tempo de antecedência é normalmente adotado para o consumo de alimentos antes da atividade física matinal. A Figura 1 apresenta os índices de resposta da quinta questão.

A sexta pergunta foi elaborada visando diagnosticar o tipo de atividade física praticada. Através desta questão foi possível observar que a atividade mais praticada entre os avaliados é a musculação $(55,2 \%)$, seguida por caminhada (30\%), futebol (14,8\%), atletismo (12\%), ciclismo $(12,4 \%)$ e corrida $(11,2 \%)$. Os percentuais somam acima de $100 \%$ devido à presença de mais de uma atividade praticada por pessoa. Foram citadas outras atividades, como ginástica aeróbica, rpm, natação, ioga, basquete, hidroginástica, localizada, voleibol e lutas (caratê e judô).

A questão 7 investigou sobre o tempo de duração do exercício, pois este fator interfere diretamente na tomada de decisão sobre a conduta nutricional adotada, prévia ao exercício. Os resultados indicam que a maioria das pessoas pratica sua atividade física entre $60 \mathrm{~min}$ e $90 \mathrm{~min}$ (40,8\% dos entrevistados), enquanto $26 \%$ realizam o exercício com mais de $90 \mathrm{~min}$.

A oitava pergunta foi elaborada visando identificar a frequência semanal da prática de exercícios. Os resulta-

Figura 2 - Auto-percepção do nível de esforço físico entre os avaliados




dos mostram que $40 \%$ dos sujeitos praticam exercícios três vezes na semana e 53,4\% o fazem cinco vezes ou mais.

Já a nona questão perguntava sobre a percepção de esforço dos entrevistados, variando desde uma intensidade "muito leve" até "extremamente intensa", com o índice de resposta indicado na Figura 2.

A décima pergunta foi elaborada para diagnosticar a prevalência de sintomas e sinais que se relacionam a situações de hipoglicemia e desidratação, com os índices de resposta apresentados na Figura 3.

A décima primeira questão procurou conhecer o número de pessoas que fazem uso ou não de suplementos nutricionais e, se usam, quais seriam? Nesta questão foi possível verificar que $28,2 \%(n=141)$ dos indivíduos avaliados fazem uso de suplementos "da moda". A Figura 4 apresenta os tipos de suplementos "da moda" mais utilizados.

A décima segunda questão avaliou se os entrevistados já mensuraram a glicemia capilar antes ou após a prática de exercícios. A maioria das pessoas (85\%) nunca passou pela experiência de mensuração da glicose capilar, antes ou após o exercício.

A décima terceira questão refere-se à hidratação adotada antes, durante e após o exercício. Os resultados indicam que a maior parte das pessoas $(90,4 \%)$ se hidrata ao praticar atividade física. Um total de 8,4\% afirmou nunca se hidratar e 1,2\%, somente às vezes.

A Figura 5 mostra o índice de resposta da décima quarta questão, sobre os momentos em que os entrevistados se hidratam.

A décima quinta questão procurou verificar os tipos de solução hidratante utilizados ao praticar exercícios. Pôde ser observado que a água é o líquido mais consumido pelos praticantes de atividade física entrevistados $(87,8 \%)$, seguido pela bebida carboidratada, com 18,5\%.

\section{DISCUSSÃO}

A maior parte do grupo avaliado (82,2\%) informou que consome algum tipo de alimento antes de iniciar uma atividade física matinal. Esse resultado difere do

Figura 3 - Manifestações fisiológicas já ocorridas durante a prática de atividade física

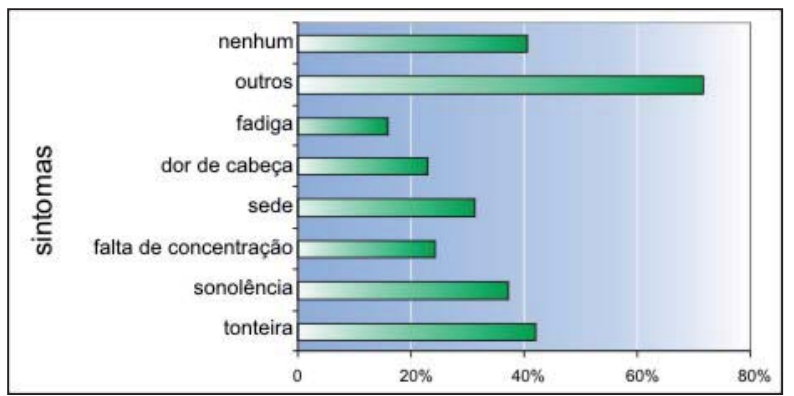

encontrado por Néri et al..$^{\mathbf{2 5}}$ que, em uma amostra de 264 maratonistas, observaram que $61 \%$ iniciam um treino após um lanche e um total de 39\% o faz em jejum. Ferreira et al. ${ }^{26}$ encontraram um percentual ainda menor de pessoas que praticam atividade física em jejum (2,52\%), numa amostra de 127 indivíduos praticantes de atividade física em academia na cidade de Viçosa - MG.

Entre as justificativas para a omissão do desjejum apresentadas pelos avaliados do presente estudo, estão: incômodo em fazer exercícios com alimento no estômago; treinar muito cedo; falta de apetite pela manhã; e preguiça de acordar mais cedo só para se alimentar antes do exercício físico.

Chryssanthopoulos \& Williams ${ }^{27}$ recomendam, após uma noite de jejum, a ingestão de $2,5 \mathrm{~g}$ a $4 \mathrm{~g}$ de carboidratos por $\mathrm{kg}$ de peso, de $3 \mathrm{~h}$ a $4 \mathrm{~h}$ antes do exercício, para melhorar a performance. Essa recomendação tornase inviável, na prática, para as pessoas que realizam exercícios entre $5 \mathrm{~h}$ e $7 \mathrm{~h}$ da manhã, o que representaria ter que despertar muito cedo para realizar a refeição prévia ao exercício. Geralmente, essas recomendações são indicadas para atletas profissionais, que dispõem de maior flexibilidade de horário para treinamento.

Williams ${ }^{\mathbf{2 8}}$ preconiza também que, caso o consumo energético aconteça com $60 \mathrm{~min}$ prévios ao exercício, o consumo de carboidratos deverá ser entre 1 e $2 \mathrm{~g} \cdot \mathrm{kg}^{-1} \mathrm{de}$ peso corporal, o que poderia aprimorar a performance.

Deve-se destacar que a recomendação é buscar um nutricionista, pois a composição da refeição pré-exercício vai depender de fatores, como horário de início do exercício, duração da atividade física, intensidade, modalidade esportiva, além de fatores individuais, como a tolerância gástrica, o tempo disponível para realizar a refeição e as preferências alimentares.

Os entrevistados apontaram pães $(88,07 \%)$ e frutas $(67,15 \%)$ como os alimentos consumidos de forma mais habitual. Esses resultados são semelhantes aos encontrados por Ferreira et al. ${ }^{\mathbf{2 6}}$ que, em uma amostra de 127 pessoas, observaram que $61,47 \%$ consumiam alimentos ricos em carboidratos (frutas e pão) antes do exercício, este último um nutriente essencial para a atividade física,

\section{Figura 4 - Tipos de suplementos mais utilizados}

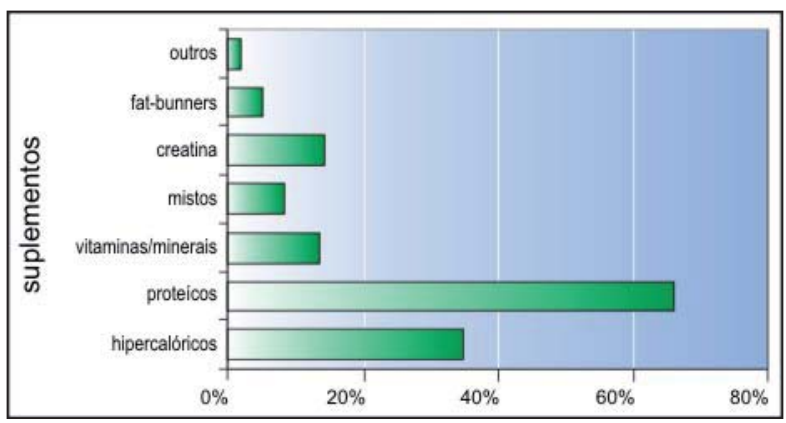


visto que sua função é fornecer energia para a realização e manutenção da mesma ${ }^{6}$.

Devido a essa importante função dos carboidratos no exercício, a SBME ${ }^{8}$ recomenda de 5 a $10 \mathrm{~g} \cdot \mathrm{kg}^{-1}$ de peso corporal por dia, para praticantes de atividade física com nível de treinamento de moderado a intenso. Essa recomendação varia de acordo com o tipo, a duração da atividade física e o objetivo do indivíduo (recuperação do glicogênio muscular, aumento da massa magra, competição).

Uma preocupação sobre a ingestão de carboidratos antes do exercício é a rápida elevação da glicose sanguínea e o efeito rebote da insulina, o que pode causar hipoglicemia no início da atividade física ${ }^{29}$. Portanto, não é qualquer carboidrato que seria indicado para compor a refeição pré-exercício. Num estudo com seis mulheres não-atletas que ingeriram $75 \mathrm{~g}$ de carboidrato na forma de cereal (um com flocos de aveia possuindo $7 \mathrm{~g}$ de fibra, e outro com farinha de aveia com $3 \mathrm{~g}$ de fibra), verificaram que a resposta insulínica $45 \mathrm{~min}$ após a refeição foi significativamente menor para a refeição com maior teor de fibra, além de o tempo de exercício antes da exaustão ter sido maior ${ }^{30}$. Esse estudo reforça que carboidratos com maior teor de fibra são mais recomendáveis para serem ingeridos antes da atividade física, como é o caso de pão, biscoitos e cereais integrais.

Entre os alimentos líquidos, o café $(51,5 \%)$ e as preparações com leite (exemplo: leite com achocolatado, com $36,36 \%$ ) estiveram mais presentes. $O$ café também foi a bebida preferida de corredores antes de iniciar a corrida, em um estudo feito na Alemanha com corredores de ultraendurance no ano de $2006^{31}$.

A cafeína presente no café tem sido relacionada a um efeito desidratante ${ }^{32}$, o que pode comprometer o estado de hidratação, principalmente se o ambiente for de estresse térmico de calor ou o praticante produzir volume elevado de sudorese. Por outro lado, a cafeína tem sido associada à melhora do desempenho físico em diversas modalidades ${ }^{33}$, e os possíveis efeitos ergogênicos estão relacionados a efeito direto no sistema nervoso central, nos co-produtos do músculo esque-

Figura 5 - Momentos em que os entrevistados se hidratam ao se exercitarem

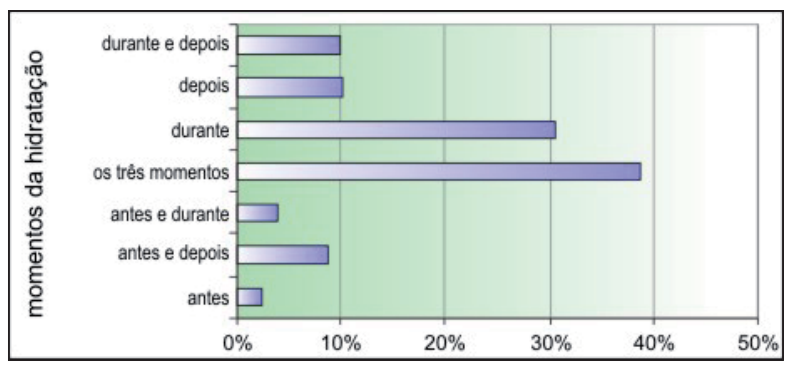

lético (alteração dos íons sódio e potássio, regulação metabólica de enzimas e aumento da mobilização de cálcio) e diminuição da oxidação de carboidratos e aceleração da mobilização dos ácidos graxos livres como substrato energético, o que pode ser interessante para pessoas que desejam emagrecer e reduzir o percentual de gordura corporal $\left.\right|^{34,35}$.

O leite, por conter proteína e gordura (quando é do tipo integral), tende a diminuir o esvaziamento gástrico ${ }^{29}$, podendo ocasionar um desconforto durante a atividade, sobretudo se esta é de alta intensidade. O leite, se desnatado, pode ser ingerido com um intervalo de tempo entre ingestão e início do exercício de pelo menos $60 \mathrm{~min}$ (este tempo costuma ser individual, dependendo da sensibilidade de cada um). O suco de frutas apresentou prevalência de 14,11\%, sendo o mais indicado. O consumo de frutose antes do exercício não causa aumento na glicose sanguínea nem na insulina ${ }^{36}$, podendo assim ser uma excelente opção pré-exercício.

Com relação aos acompanhamentos, os frios (presunto, queijos) estiveram presentes em um percentual elevado (36\%). Esse resultado é semelhante ao observado por Ferreira et al. ${ }^{26}$, que encontraram para os alimentos ricos em proteína e gordura um consumo de 20,17\% entre os seus avaliados, e por Knechtle \& Schulze ${ }^{31}$, os quais observaram entre os alimentos preferidos pelos corredores como acompanhamento, o queijo e a manteiga. Esses alimentos causam retardo no esvaziamento gástrico devido ao alto teor de proteína e gordura ${ }^{1}$, podendo gerar desde um desconforto gástrico e/ou intestinal até mal-estar, vômito e diarreia, não sendo, portanto, indicados para um consumo pré-exercício imediato. Entretanto, o consumo destes é tão possível quanto maior for o intervalo entre a ingestão e o início da atividade. Deve-se considerar que esse intervalo de tempo, para que ocorra a adequada digestão desses alimentos, é individual. De maneira geral, recomenda-se um intervalo superior a $60 \mathrm{~min}$.

No item "Outros" estão incluídos, em relação aos alimentos sólidos: biscoito de sal; salada de frutas; torrada; macarrão; pastel; barra de cereal; e até um almoço, totalizando 12,16\%. Em relação aos líquidos, com 12,4\%, foi observado: leite com café; capuccino; chá; refrigerante; isotônico; e "shakes" de proteína e/ou carboidrato. E, em relação aos acompanhamentos, foram citados: clara de ovo; geleia; chocolate; e mel. O grande condicionante para esses alimentos serem ou não recomendados, é o intervalo entre ingestão e início do exercício, o que deve ser planejado e aconselhado por um nutricionista.

Existem recomendações ${ }^{6,7}$ para um consumo de líquidos de 5 a $7 \mathrm{ml} . \mathrm{kg}^{-1}$ de peso corporal nas $4 \mathrm{~h}$ que antecedem o exercício. Entretanto, isso é de difícil concretização quando o exercício é praticado nas primeiras horas da manhã. 
A resposta da terceira pergunta apontou que a maioria dos entrevistados $(66,66 \%)$ considera que sua refeição pré-exercício contém os alimentos corretos, resultado semelhante ao encontrado por Neri et al. ${ }^{25}$, em cujo estudo, dos 264 maratonistas entrevistados, 66\% acreditaram ter uma alimentação balanceada e correta. Contudo, de acordo com os alimentos apresentados na questão anterior, pode-se observar que muitos são equivocados no tocante a essa opinião, devido à presença de alimentos não recomendados. Cabe destacar, porém, que $33,4 \%$ dos avaliados no presente trabalho consideram que a alimentação pré-exercício não é ideal devendo ser modificada. A solução para esse tipo de problema é a busca de um aconselhamento por meio de um nutricionista especializado na área esportiva, que irá adequar a refeição de acordo com a energia consumida durante o exercício, o esvaziamento gástrico individual, a intensidade, as preferências, os hábitos, a acessibilidade a determinados alimentos, entre muitos outros fatores. Essas orientações visam dar maior conforto e bem-estar, garantindo uma alimentação mais saudável e equilibrada.

Foi notado, no índice de respostas obtido na pergunta quatro, que muitas pessoas creem que um alimento, por ser saudável, pode fazer parte de seu desjejum prévio ao exercício. No entanto, esse conceito está equivocado, pois são indicados, para esta refeição, alimentos ricos em carboidratos complexos ${ }^{37}$, geralmente de baixo a moderado índice glicêmico ${ }^{38}$, ou, se for carboidrato simples (de alto índice glicêmico), que seja frutose, como as frutas e seus sucos, que são de fácil digestão e fornecem energia rapidamente sem causar um elevado pico glicêmico e insulinêmico. Os alimentos ricos em outros carboidratos simples, como a sacarose, devem ser evitados, já que podem provocar hiperinsulinemia e, em consequência, uma "hipoglicemia de rebote" pode acontecer ${ }^{39}$, gerando sintomas, desde um mal-estar até um desmaio.

Alimentos ricos em proteína (frios: queijo, presunto, mussarela, ricota) e/ou gordura (manteiga, margarina, presunto e queijos), que juntos somam $40 \%$, além da possibilidade de causar desconforto gástrico, não são fontes de energia rapidamente disponíveis. Logo, devem ser evitados ou consumidos em pequenas quantidades, dependendo do intervalo de tempo entre o fim da refeição e o início do exercício.

A Figura 1 mostra que a maior parte dos entrevistados que realizam o desjejum pré-exercício o fazem entre $15 \mathrm{~min}$ e $30 \mathrm{~min}$ antes do exercício (34\%). Isso demonstra um tempo relativamente pequeno que a maioria das pessoas tem para realizar essa refeição. Cocate et al. ${ }^{40}$, ao analisarem o comportamento da glicemia sanguínea através de um coletor de sangue periférico por polpa digital, verificaram aumento significativo da glicose no período de $30 \mathrm{~min}$ após a ingestão de dois tipos de café-da-manhã, apresentando, em seguida, uma queda brusca, voltando aos valores de jejum após 60 min do aporte energético, porém com tendência a redução nos primeiros $20 \mathrm{~min}$ de atividade. Esse comportamento da glicemia pode ter sido desencadeado pela hiperinsulinemia, estimulada a partir da concentração de glicose sanguínea superior a $110 \mathrm{mg} \cdot \mathrm{dl}^{-1} \mathbf{4 1}^{\mathbf{4 1}}$. Isso justifica a recomendação do intervalo entre a refeição e o exercício não ser próximo aos $30 \mathrm{~min}$, já que existe tempo suficiente para elevar rapidamente a glicemia, o que poderia adicionar dois fatores hipoglicemiantes: a resposta insulínica e o exercício. Entretanto, certas adaptações individuais podem interferir nessa recomendação, tendo em vista que o trabalho de DeVlin et al. ${ }^{\mathbf{} 2}$ mostrou que um lanche rápido composto por macronutrientes mistos, consumido $30 \mathrm{~min}$ antes do exercício, mesmo influenciando a resposta insulínica não foi suficiente para modificar o desempenho físico em jovens não-treinados.

Os alimentos permitidos para esse intervalo de tempo são fontes de carboidrato de digestão mais rápida, como pães, frutas, suco de frutas, geleias, mel, cereais, cereais em barra e, até mesmo, suplementos de carboidratos (gel de carboidrato e bebidas carboidratadas) em quantidade suficiente para não causar um desconforto gástrico e de acordo com o gasto energético em atividade física, o que varia de pessoa para pessoa. É importante frisar que, quanto menor o intervalo de tempo entre o término da refeição e o início do exercício, mais limitado é o consumo de alimentos com elevados teores de gordura e proteína, como manteiga, margarina, queijo, presunto e ovos, os quais apresentam maior tempo de digestão, podendo ocasionar desconforto abdominal e gástrico'.

Um critério interessante para estabelecer a seleção dos alimentos que devem compor a refeição matinal prévia ao exercício, refere-se ao índice glicêmico. Os alimentos com baixo índice glicêmico produzem menor elevação da glicose sanguínea e, consequentemente, menor estímulo insulínico, como observado por Marins et al..$^{43}$

Outro fator a ser considerado é o volume ingerido, que parece ser o mais importante na regulação do esvaziamento gástrico ${ }^{44}$. Tem-se ainda a consistência do alimento ingerido e a intensidade da atividade física realizada, visto que ambos podem influenciar a taxa de esvaziamento gástrico da refeição ${ }^{45}$. Tem sido demonstrado aumento linear na taxa de esvaziamento gástrico (velocidade de passagem do alimento pelo estômago) com o aumento no conteúdo gástrico máximo de $600 \mathrm{ml}$ a $700 \mathrm{ml}$ de ingestão, o que equivale a 8 a $10 \mathrm{ml} . \mathrm{kg}^{-1}$ de peso corporal| ${ }^{46,47}$. 
Uma orientação nutricional prévia a uma atividade física matinal deve considerar o intervalo de tempo entre o consumo de alimentos e o início do exercício. Caso esse intervalo seja inferior a $60 \mathrm{~min}$, sugere-se uma atenção especial quanto a volume, densidade calórica e forma física (líquido e/ou sólido), a fim de evitar uma plenitude gástrica ou risco de hipoglicemia de rebote.

Para o grupo de entrevistados que consomem alimentos imediatamente antes do exercício (12\%), o tipo de alimento indicado deve ser preferencialmente na forma líquida, podendo ser de alto índice glicêmico, pois não haverá mais o risco de hipoglicemia de rebote ${ }^{32}$. Já para $21 \%$ dos entrevistados, que consomem alimentos com $1 \mathrm{~h}$ de antecedência, o consumo de carboidratos deve ser limitado entre 1 a $2 \mathrm{~g} \cdot \mathrm{kg}^{-1}$ de peso corporal ${ }^{\mathbf{2 8}}$.

O perfil de entrevistados neste estudo foi originário de praticantes de diferentes modalidades esportivas. O tipo de atividade física realizada pode influenciar diretamente a recomendação nutricional prévia ao exercício, tendo em vista dois aspectos: a intensidade da atividade e as ações motoras realizadas. Quando um exercício é realizado a uma intensidade superior a $80 \% \mathrm{VO}_{2 \text { máx' }}$ tem-se uma redução da capacidade de esvaziamento gástrico ${ }^{6}$, o que facilita o aparecimento de sensações de plenitude gástrica, náuseas, reflexos e vômitos. Assim, no caso de treinos de alta intensidade, típicos no ciclismo, corrida, natação, futebol e lutas, deve haver uma atenção especial quanto ao volume consumido de alimentos.

Já a ação motora também pode influenciar, por exemplo, em exercícios com inversão da posição corporal, típicos da ginástica artística ou natação sincronizada, ou mesmo a natação, por parte de sua horizontalidade, o que facilita um refluxo gástrico. $\bigcirc$ exercício de corrida gera impactos no solo, com vibração em todo o sistema gastrointestinal, o que em certas pessoas pode produzir desconforto gástrico, situação esta diferente do ciclismo, onde não existe vibração, permitindo um consumo de alimentos de perfil diferenciado.

Atividades de baixo impacto e intensidade, como o ioga, treinamento de flexibilidade, certas ginásticas e musculação, podem oferecer maior variedade para prescrever ações nutricionais.

A sétima pergunta do questionário aponta que a maior parte do grupo $(68,8 \%)$ realiza exercícios físicos com mais de 60min de duração, ampliando a possibilidade do aparecimento de um quadro de hipoglicemia caso o exercício seja feito em jejum. No presente estudo, $17,8 \%$ dos entrevistados afirmaram realizar o exercício matinal em jejum, valor próximo ao obtido por Coelho et al. ${ }^{\mathbf{3 8}}$, que foi de $18 \%$. Nessas condições, existe um risco elevado de hipoglicemia, principalmente se, durante o exercício, não ocorrer um consumo energético.
Cabe destacar que, dependendo da intensidade, em conjunto ao tempo pode ocasionar riscos de hipoglicemia e fadiga ${ }^{39}$.

Por outro lado, a realização do exercício em jejum até $60 \mathrm{~min}$ não foi considerada crítica por Marins et al. ${ }^{43}$, Cocate \& Marins ${ }^{48}$ e Cocate et al..$^{40}$. Contudo, esses autores apontam que as condições específicas dos estudos que foram realizados podem ter influenciado esse resultado, tendo em vista o perfil populacional composto por homens jovens em idade universitária, ativos, não submetidos a dietas restritivas, em exercício de média intensidade e duração de 60min.

Deve-se ter claro que, caso não seja consumido nenhum alimento prévio ao exercício, o consumo de bebidas esportivas, gel ou barras energéticas durante o exercício, principalmente quando este durar mais de $60 \mathrm{~min}$, é fundamental para a qualidade da atividade, pois evitará um estado de hipoglicemia. Isso fica claro no trabalho de Marins et al. ${ }^{43}$, em que o consumo de uma bebida esportiva durante o exercício de $1 \mathrm{~h}$ proporcionou melhor resposta da curva glicêmica, mesmo iniciando o exercício em jejum, em relação ao consumo de alimentos $1 \mathrm{~h}$ antes do treinamento, tanto de alto como de baixo índice glicêmico, porém hidratando com água ao longo da atividade.

Os entrevistados apresentaram que $40 \%$ dos sujeitos praticam exercícios três vezes na semana, e 53,4\% o fazem cinco vezes ou mais. Trata-se de um resultado positivo, mostrando o interesse das pessoas e a assiduidade à prática de atividade física, estando em conformidade com as atuais recomendações internacionais de prática de atividade física ${ }^{49}$. Esse comportamento aumenta ainda mais a importância da realização de um consumo energético diário equilibrado, não sendo recomendado "saltar" uma refeição. Neste caso, a que antecede o início da atividade física.

Treinamentos diários aumentam o risco de um estado de desidratação crônica, por um baixo consumo de líquidos durante e após o exercício?. Assim, neste perfil de praticante, o consumo matinal de uma refeição contendo líquidos pode atenuar um quadro de desidratação crônica.

A Figura 2 permite avaliar que a grande maioria considera sua atividade física como de intensidade moderada. Esse resultado, para praticantes de atividade física no conceito "saúde", pode ser considerado o mais correto, de acordo com o observado na questão 7 sobre o tempo de duração do exercício físico, em que grande parte dos avaliados afirmou ser de $60 \mathrm{~min}$ a 90 min por dia.

A intensidade da atividade física praticada exerce influência no tipo de desjejum que deverá ser escolhido como refeição prévia ao exercício. Para exercícios de 
baixa intensidade (menor que $50 \%$ do $\mathrm{VO}_{2 \text { máx }}$ ), como caminhadas, o principal substrato energético é a gordura (ácidos graxos livres e triglicerídeos musculares), e, portanto, bastaria uma refeição leve, como uma fruta (a frutose não é hiperinsulinêmica) ${ }^{39}$. Em exercícios prolongados, sob intensidades moderadas a elevadas (maior que $65 \%$ do $\mathrm{VO}_{2 \text { máx }}$ ), como corrida e ciclismo, ocorre primeiramente um intenso gasto de glicogênio muscular, concomitante ao da glicose sanguínea, o que pode levar à fadiga, caso a refeição prévia ao exercício não tenha uma quantidade satisfatória de carboidratos. Já em exercícios intermitentes, como a musculação, a energia é obtida pelo metabolismo anaeróbico. Nesse caso, os carboidratos contribuem com cerca de $2 / 3$ do total de energia gerada, depletando também os estoques de glicogênio, o que sugere uma refeição com carboidratos integrais, para a energia ser liberada aos poucos ${ }^{39}$.

A Figura 3 informa os sintomas mais apresentados pelas pessoas entrevistadas. Os de maior prevalência, foram tonteira, "nenhum" (nunca sentiu nada), sonolência e sede intensa. As manifestações apresentadas somam mais de $100 \%$, pelo fato de cada pessoa ter apresentado, muitas vezes, mais de uma manifestação fisiológica. Marins et al. ${ }^{\mathbf{5 0}}$ encontraram, como manifestações fisiológicas mais frequentes em um questionário sobre hidratação, a "sede muito intensa" (23,45\% dos fundistas, 53,5\% dos triatletas e 53\% dos ciclistas) e a "fadiga generalizada" (34,9\% dos fundistas, 53,5\% dos triatletas e $36 \%$ dos ciclistas).

$\bigcirc$ item "Outros" contém os seguintes sintomas: alterações visuais; interrupção da produção do suor; desmaio; vômito; náusea; alucinações; olhos fundos; perda momentânea da consciência; palidez; desconforto gástrico e dificuldade de realização de movimentos. Não foi encontrado nenhum sintoma grave, como convulsão, mas foram encontrados três relatos de desmaio. Acreditase que esses sintomas podem ser minimizados com uma hidratação adequada antes, durante e após os treinos ${ }^{6}$, bem como também com uma refeição adequada previamente ao exercício ${ }^{7}$, ou pelo menos uma reposição alimentar durante este ${ }^{\mathbf{5}}$.

consumo de suplementos foi apontado por 28,2\% dos indivíduos avaliados. Esse resultado se assemelha ao do estudo de Ferreira et al. ${ }^{\mathbf{2 6}}$, em que $17,18 \%$ da sua população consumia suplementos. Já no trabalho de Dominguez \& Marins ${ }^{\mathbf{2 3}}$, com 200 praticantes de musculação em Belo Horizonte - MG, os índices obtidos foram 48\% de forma contínua e 30\% esporadicamente. Já em Petroczi \& Naughton"1 a prevalência foi de 58,8\% de um total de 847 atletas de alta performance, enquanto 98,6\% foram obtidos em estudantes atletas universitários canadenses ${ }^{51}$. Esses resultados apontam que o perfil de modalidade ou o ambiente de sua realização podem exercer alguma influência sobre a prevalência do consumo de suplementos. tipo mais consumido pelos sujeitos entrevistados foi de suplementos proteicos, com 65,9\%, porém diferente quando comparado ao estudo de Ferreira et al. ${ }^{\mathbf{2 6}}$, em que os suplementos proteicos contribuíram com 30,77\%. No trabalho de Petroczi \& Naughton ${ }^{11}$, os produtos mais consumidos foram os complexos multivitamínicos $(72,6 \%)$, vitamina C $(70,7 \%)$, creatina $(36,1 \%)$ e Whey Protein $(31,7 \%)$.

Entre os glicídicos (carboidratos) e energéticos, foram citados pelos entrevistados: soluções de carboidratos (isotônicos); maltodextrina; carboidratos em gel e em pó (Mega Mass). Entre os proteicos: albumina; BCAA; glutamina; protein bar; Whey Protein e extrato de soja. Em "Outros", inclui: creatina; carnitina; glutamina; e esteroides anabólicos.

É interessante destacar que o glicerol não foi mencionado pelos entrevistados. Esse recurso é apontado normalmente como uma estratégia para retenção de líquidos, prévia ao exercício ${ }^{\mathbf{5 2}}$. Contudo, seu consumo vem sendo associado a efeitos ergolíticos, não sendo recomendado 6 .

presente estudo apontou que $67 \%$ dos entrevistados já fizeram ou fazem uso de suplementos proteicos. Essa prevalência deve ser analisada com cautela, indicando que a população ainda possui o conceito de supervalorizar o papel da proteína para o rendimento esportivo. Esse comportamento também foi semelhante em treinadores de várias modalidades ${ }^{18}$, assim como em militares americanos ${ }^{53}$, sendo este um indicador importante para uma orientação nutricional por um profissional. Cabe destacar que uma alimentação bem planejada pode ser totalmente suficiente para repor as necessidades diárias, na maioria dos casos.

A mensuração da glicemia capilar é um procedimento importante para diagnosticar corretamente o efeito de um consumo de alimentos prévio ao exercício. Um total de $85 \%$ dos avaliados nunca passou pela experiência de mensuração da glicose capilar antes ou após o exercício. Entre os que responderam afirmativamente, alguns citaram que, em determinadas competições, a organização levou o medidor de glicose e fez testes nos competidores, antes ou após as provas. Essa seria uma atitude interessante para prevenir casos de hipoglicemia pré-evento ou pós-evento, tendo uma equipe preparada para diagnóstico e tratamento (oferecimento de alimentos corretos).

Sugere-se que seja adotada, no acompanhamento nutricional, a dosagem de glicemia capilar em intervalos regulares entre $20 \mathrm{~min}$ e 30 min durante o exercício, observando a resposta glicêmica da ação nutricional matinal frente ao exercício, permitindo assim uma maior precisão na prescrição dietética. Isso é necessário, pois há indícios de que certos sujeitos são mais propensos a uma resposta 
de hipoglicemia de rebote ${ }^{54}$, o que implicaria um estudo de sua cinética glicêmica.

A maior parte das pessoas entrevistadas $(90,4 \%)$ se hidrata ao praticar atividade física, o que é um bom resultado, assemelhando-se ao encontrado por Brito \& Marins ${ }^{55}$. Contudo, um total de $8,4 \%$ afirmou nunca se hidratar e 1,2\% somente às vezes, assemelhando-se ao encontrado por Marins et al. ${ }^{\mathbf{5 0}}$, em que $11,4 \%$ dos fundistas e $7 \%$ dos ciclistas não tinham o costume de se hidratar ao se exercitar.

Entre os sujeitos que relataram no presente estudo que não consomem líquidos e que também devem estar realizando o exercício em jejum, de longa duração, de média e alta intensidade $(8,4 \%)$, os riscos de desidratação e, principalmente, de hipoglicemia, são elevados. Assim, deve haver um trabalho de intervenção, evitando esse quadro em uma parcela importante do grupo avaliado.

A Figura 5 revela que nem sempre os entrevistados hidratam-se corretamente, ou seja, antes, durante e depois da sessão de exercícios. Isso evitaria que iniciassem a atividade física já desidratados, ou mesmo minimizaria a ocorrência de desidratação durante o exercício, por repor os líquidos perdidos com o suor. Marins et al. ${ }^{50}$ afirmaram que $50,5 \%$ dos fundistas se hidratam antes e após os treinos e $55 \%$ dos triatletas o fazem somente após. É importante iniciar uma sessão de exercícios num estado hidratado ${ }^{5} \mathrm{e}$ manter uma correta hidratação durante e após, recuperando um possível estado de desidratação ${ }^{50}$. Uma ação nutricional matinal prévia ao exercício, contendo líquidos, pode ser importante para auxiliar na pré-hidratação, sobretudo quando o exercício for realizado em clima quente 9 .

Havemann \& Goedecke ${ }^{13}$, em ciclistas de ultraendurance, observaram que o consumo de $\mathrm{CHO}$ antes de uma prova de $210 \mathrm{~km}$ correspondia a $84 \%$ dos avaliados, sendo $98 \%$ durante a prova, refletindo assim a importância do consumo desse nutriente.

É interessante destacar que, em muitos casos, os treinadores são protagonistas na indução de condutas nutricionais inadequadas pelos atletas. Como exemplo, tem-se o trabalho de Juzwiak \& Ancona-López ${ }^{18}$, em que $27 \%$ dos treinadores aconselhavam procedimentos de restrição hídrica ou não adotavam estratégias nutricionais específicas para antes, durante e depois da atividade.

A preferência do consumo de líquidos está voltada para a água $(87,8 \%)$ e bebidas carboidratas $(18,5 \%)$. Resultado semelhante foi encontrado por Marins et al..$^{\mathbf{5 0}}$, em que os fundistas costumavam ingerir água antes e após a sessão de exercícios e 20,5\% deles costumavam consumir bebidas carboidratadas durante os treinos.

Durante o exercício, o consumo exclusivo de água somente deve ser indicado para atividades com menos de $60 \mathrm{~min}$ de duração ${ }^{8}$. Para aquelas com tempo maior, o consumo de bebidas carboidratadas será uma solução para evitar um quadro hipoglicêmico ${ }^{43}$, principalmente se o indivíduo não fez uma correta refeição pré-exercício ou faz uso de dietas restritivas.

Cerca de $8,8 \%$ dos entrevistados tomava suco de frutas durante a atividade física. A frutose, apesar de não insulinêmica, poderia ser indicada antes do exercício. Seu uso durante a sessão de exercícios pode causar desconforto gastrintestinal ${ }^{29}$.

Os resultados obtidos no presente trabalho permitem concluir que os praticantes de atividade física matinal habitualmente consomem algum alimento antes da prática de exercícios, sendo em sua maioria em estado sólido, normalmente incluindo pães e frutas. Contudo, constam alimentos nem sempre recomendáveis, pelo alto teor de gorduras e proteínas. Também consideram sua escolha de alimentos de forma adequada. O tempo prévio de consumo de alimentos antes do exercício matinal corresponde, em sua maioria, a até $30 \mathrm{~min}$.

Pode-se concluir também que às características da atividade física praticada, de longa duração, de intensidade moderada e de elevada assiduidade, implicam uma orientação nutricional adequada para a primeira refeição do dia.

Faz-se necessária uma melhor orientação em relação à alimentação adequada prévia ao exercício, com o auxílio de um nutricionista esportivo e campanhas informativas. Isso contribuirá para criar hábitos de condutas nutricionais mais adequadas, melhorando assim a performance e a qualidade da atividade realizada.

\section{REFERÊNCIAS}

1. Willians SR. Fundamentos de nutrição e dietoterapia. Porto Alegre: Artes Médicas; 1997.

2. National Athletic Trainers' Association (NATA). Position statement: preventing, detecting, and managing disordered eating in athletes. J Athl Train. 2008;43(1):80-108.

3. Pollitt E. Does breakfast make a difference in school? J Am Diet Assn. 1995;95:1134-9.

4. Carmuega E. Café-da-manhã, muito mais que um hábito saudável. Informativo Saúde \& Nutrição. 2003;13(14):1-10.

5. Maughan RJ, Burke LM. Nutrição esportiva. São Paulo: Artmed; 2004.

6. Spanish Federation of Sport Medicine (SFSM). Consensus on drinks for the sportsman. Composition of guidelines of replacement of liquids. Consensus document of the Spanish Federation of Sports Medicine Archivos de Medicina del Deporte. 2008; 25(4):245-58.

7. American College of Sports Medicine (ACSM): Position stand: exercise and fluid replacement. Med Sci Sports Exerc. 2007;39(2):377-390.

8. Sociedade Brasileira de Medicina do Esporte (SBME). Diretrizes. Modificações dietéticas, reposição hídrica, suplementos alimentares e drogas: comprovação de ação ergogênica e potenciais riscos para a saúde. Rev Bras Med Esporte. 2003;9(2):43-56.

9. National Athletic Trainers' Association (NATA). Position statement: fluid replacement for athletes. J Athl Train. 2000;35(2):212-24.

10. Brasil TA, Cocate PG, Marins JCB. Consumo alimentar pré-exercício de praticantes de atividade física matinal. Em: II Fórum Brasileiro de Educação 
Física e Ciências do Esporte - VI Simpósio Mineiro de Ciências do Esporte 2004, Viçosa-MG. Revista Mineira de Educação Física. 2004;12(2):536.

11. Petroczi A, Naughton DP. The age-gender-status profile of high performing athletes in the UK taking nutritional supplements: lessons for the future. J Int Soc Sports Nutr. 2008; 10(5):2.

12. Rose SC, Peters EM. Ad libitum adjustments to fluid intake in cool environmental conditions maintain hydration status in a three-day mountain bike race. Br J Sports Med. Epub 2008 jun 6.

13. Havemann L, Goedecke JH. Nutritional practices of male cyclists before and during an ultraendurance event. Int J Sport Nutr Exerc Metab. $2008 ; 18(6): 551-66$.

14. Fudge BW, Easton C, Kingsmore D, Kiplamai FK, Onywera VO, Westerterp $K R$, et al. Elite Kenyan endurance runners are hydrated day-to-day with ad libitum fluid intake. Med Sci Sports Exerc. 2008;40(6):1171-9.

15. Cabral CAC, Rosado GP, Osorio CH, Marins JCB. Diagnóstico do estado nutricional dos atletas da equipe olímpica permanente de levantamento de peso do Comitê Olímpico Brasileiro (COB). Rev Bras Med Esporte. $2006 ; 12(6): 345-50$.

16. García-Rovés PM, Terrados N, Fernández S, Patterson AM. Comparison of dietary intake and eating behavior of professional road cyclists during training and competition. Int J Sport Nutr Exerc Metab. 2000;10(1):82-98

17. Zinn C, Schofield G, Wall C. Evaluation of sports nutrition knowledge of New Zealand premier club rugby coaches. Int J Sport Nutr Exerc Metab. 2006;16(2):214-25.

18. Juzwiak CR, Ancona-Lopez F. Evaluation of nutrition knowledge and dietary recommendations by coaches of adolescent Brazilian athletes. Int J Sport Nutr Exerc Metab. 2004;14(2):222-35

19. Brito ISS, Diniz A, Brito CJ, Marins JCB. Caracterização das práticas e hábitos de hidratação em lutadores brasileiros de jiu-jitsu. Coleção Pesquisa em Educação Física. 2007;6:153-60.

20. Brito ISS, Fabrini SP, Brito CJ, Marins JCB. Caracterização das práticas de hidratação em caratecas do estado de Minas Gerais. Fit Perf J. 2006;5(1):24-30.

21. Brito CJ, Marins JCB. Caracterização das práticas sobre hidratação em atletas da modalidade de judô no estado de Minas Gerais. Rev Bras Ciênc Mov. 2005;13(2):59-74.

22. Marins JCB, Ferreira FG. Nível de conhecimento dos atletas universitários da UFV sobre hidratação. Fit Perf J. 2005;4(3):175-87.

23. Domingues SF, Marins JCB. Utilização de recursos ergogênicos e suplementos alimentares por praticantes de musculação em Belo Horizonte - MG. Fit Perf J. 2007;6(4):218-26.

24. Artiolli GG, Secagliusi FB, Polacow VO, Benatti FB, Coelho DF, Vieira P, et al. Avaliação do consumo de energia e macronutrientes de atletas de judô do sexo masculino. Em: Anais do $7^{\circ}$ Congresso da Sociedade Brasileira de Alimentação e Nutrição - SBAN. Belo Horizonte; 2003.

25. Néri LCL, Scudeller JC, Honda FM, Peres MIG, Crook PO, Bertolucci P. Conhecimento em nutrição aplicada ao esporte e comportamento alimentar de maratonistas. Em: Anais do $7^{\circ}$ Congresso da Sociedade Brasileira de Alimentação e Nutrição - SBAN. Belo Horizonte; 2003.

26. Ferreira S, Lunz W, Viana EC, Da Silva LC, Silva AG. Perfil e nível de conhecimento sobre nutrição em usuários de academia. Em: Anais do $7^{\circ}$ Congresso da Sociedade Brasileira de Alimentação e Nutrição - SBAN. Belo Horizonte; 2003.

27. Chryssanthopoulos C, Willians C. Preexercise carbohydrate meal and endurance running capacity when carbohydrates are ingested during exercise. Int J Sports Med. 1997; 18(7):543-8

28. Williams M. Nutrição para saúde, condicionamento físico e desempenho esportivo. São Paulo: Manole; 2002

29. Rankin JW. Glycemic index and exercise metabolism. Gatarode Sports Science Institute [serial na Internet]. [acesso $2008 \mathrm{dez}$. Disponível em : http://www.gssiweb.com/Article_Detail.aspx?articleid=37.

30. Kirwan JP, O Gorman D, Evans WJ. A moderate glycemic meal before endurance exercise can enhance performance. J Appl Physiol. 1998;84(1):53-9.

31. Knechtle B, Schulze I. Praxis (Bern 1994). 2008;97(5):243-51.
32. Robergs $R$, Roberts $S$. Fisiologia do exercício para aptidão, desempenho e saúde. São Paulo: Editora Phorte; 2002.

33. Gutierres AP, Gatti K, Perrout JR, Alfenas RCG, Natali AJ, Marins JCB. Efeito de bebida Esportiva cafeinada sobre o estado de hidratação de jogadores de futebol. Rev Bras Ciênc Esp. 2008;29(2):147-63.

34. Sinclair CJD, Geiger JD. Caffeine use in sport: a pharmacological review. J Sports Med Phys Fitness. 2000;40(1):71-9.

35. Spriet LL. Caffeine and performance. Int J Sports Nutr. 1995;5(1):84-99.

36. Febbraio MA, Stewart KL. CHO feeding before prolonged exercise: effect of glycemic index on muscle glycogenolysis and exercise performance. J Appl Physiol. 1996;81(3):1115-20.

37. Coyle EF. Carboidratos e desempenho atlético. Gatarode Sports Science Institute [serial na Internet]. [acesso $2008 \mathrm{dez}$. Disponível em : http:// www.gssi.com.br/scripts/publicacoes/sse/sse_artigo.asp? IDTipo = 1 \&ID Publicacao $=14 \&$ DscArquivo $=$ gatoradesse $9 . \mathrm{pdf} \& \mathrm{DscArquivoH} \mathrm{tm}=/ \mathrm{SSE} /$ $\mathrm{Html} / 09 . \mathrm{htm}$

38. Coelho CF, Sakzenian VM, Burini RC. Ingestão de carboidratos e desempenho físico. Revista Nutrição em Pauta. 2004;3:51-7.

39. Mcardle WD, Katch FI, Katch VL. Fisiologia do exercício: energia, nutrição e desempenho humano. Rio de Janeiro: Guanabara Koogan; 2003.

40. Cocate PG, Brasil TA, Marins NMO, Marins JCB. Ingestão pré-exercício de um "café da manhã": efeito na glicemia sanguínea durante um exercício de baixa intensidade. Fit Perf J. 2005;4(5):261-73.

41. Guyton A. Tratado de fisiologia médica. $8^{a}$ ed. Rio de Janeiro; Guanabara; 1992.

42. Devlin JT, Calles-Escandon J, Horton ES. Effects of preexercise snack feeding on endurance cycle exercise. J Appl Physiol. 1986;60(3):980-5.

43. Marins JCB, Altoe JL, Silva RP, Ferreira FG, Makkai L, Reis FTM. Effects of pre-exercise meals on glucose kinetic before and during moderate exercise. Archivos de Medicina del Deporte. 2008;25(6):479.

44. Rehrer NJ, Beckers E, Brouns F, Ten HF, Saris WHM. Exercise and training effects on gastric emptying of carbohydrate beverages. Med Sci Sports Exerc. 1989;21(5):540-9.

45. Rombaldi AJ, Sampedro RMF. Fatores a considerar na suplementação com soluções carboidratadas. Rev Bras de Ativ Fís Saúde. 2001;6(1):53-61.

46. Costill DL, Saltin B. Factors limiting gastric emptying during rest and exercise J Appl Physiol. 1974;37(5):679-83

47. Mitchell JB, Voss KW. The influence of volume on gastric emptying and fluid balance during prolonged exercise. Med Sci Sports Exerc. 1991;23(3):314-9.

48. Cocate PG, Marins JCB. Efeito de três ações de café da manhã sobre a glicose sanguínea durante um exercício de baixa intensidade realizado em esteira rolante. Rev Bras Cineantropom Desempenho Hum. 2007;9(1):67-75.

49. Haskell WL, Lee IM, Pate RR, Powell KE, Blair SN, Franklin BA, et al. Physical activity and public health: updated recommendation for adults from the American College of Sports Medicine and the American Heart Association. Med Sci Sports Exerc. 2007;39(8):1423-34

50. Marins JC, Agudo C, Lepine MLI, Marins N, Navarro SZ. Hábitos de hidratación en un colectivo de deportistas de pruebas de resistencia. Selección. $2004 ; 13(1): 18-28$.

51. Kristiansen M, Levy-Milne R, Barr S, Flint A. Dietary supplement use by varsity athletes at a Canadian university. Int J Sport Nutr Exerc Metab. $2005 ; 15(2): 195-210$

52. Wingo J, Casa D, Berger E, Dellis W, Knight J, McClung. Influence of a preexercise glycerol hydration beverage on performance and physiologic function during mountain-bike races in the heat. J Athl Train. 2004;39(2):169-75.

53. Bovill ME, Tharion WJ, Lieberman HR. Nutrition knowledge and supplement use among elite U.S. army soldiers. Mil Med. 2003;168(12):997-1000.

54. Brouns F. Nutrição para os desportos. Rio de Janeiro: Guanabara Koogan 2005.

Recebido: 19/01/09 - Aceito: 03/04/09 